\title{
Thought-shape fusion and body image in eating disorders
}

This article was published in the following Dove Press journal:

International Journal of General Medicine

4 October 2012

Number of times this article has been viewed

\author{
Ignacio Jáuregui-Lobera' \\ Patricia Bolaños-Ríos ${ }^{2}$ \\ Inmaculada Ruiz-Prieto \\ 'Department of Nutrition and \\ Bromatology, Pablo de Olavide \\ University, Seville, Spain; ${ }^{2}$ Behavioral \\ Sciences Institute, Seville, Spain
}

Purpose: The aim of this study was to analyze the relationships among thought-shape fusion (TSF), specific instruments to assess body image disturbances, and body image quality of life in eating disorder patients in order to improve the understanding of the links between body image concerns and a specific bias consisting of beliefs about the consequences of thinking about forbidden foods.

Patients and methods: The final sample included 76 eating disorder patients (mean age $20.13 \pm 2.28$ years; 59 women and seven men). After having obtained informed consent, the following questionnaires were administered: Body Appreciation Scale (BAS), Body Image Quality of Life Inventory (BIQLI-SP), Body Shape Questionnaire (BSQ), Eating Disorders Inventory-2 (EDI-2), State-Trait Anxiety Inventory (STAI), Symptom Checklist-90-Revised (SCL-90-R) and Thought-Shape Fusion Questionnaire (TSF-Q).

Results: Significant correlations were found between TSF-Q and body image-related variables. Those with higher scores in TSF showed higher scores in the BSQ $(P<0.0001)$, Eating Disorder Inventory - Drive for Thinness (EDI-DT) $(P<0.0001)$, and Eating Disorder Inventory - Body Dissatisfaction (EDI-BD) $(P<0.0001)$. The same patients showed lower scores in the BAS $(P<0.0001)$. With respect to the psychopathological variables, patients with high TSF obtained higher scores in all SCL-90-R subscales as well as in the STAI.

Conclusion: The current study shows the interrelations among different body image-related variables, TSF, and body image quality of life.

Keywords: cognitive distortions, quality of life, body appreciation, psychopathology, anorexia nervosa, bulimia nervosa

\section{Introduction}

Body image has been defined as a multidimensional construct consisting of selfperceptions and attitudes related to one's own body, mainly but not limited to one's physical appearance. ${ }^{1,2}$ Body image attitudes are associated with different variables such as self-esteem, eating behavior, sexual behavior, and emotional stability and is influenced by specific life context and quality of life. As a result, body dissatisfaction may have negative consequences, eg, depression, anxiety, and poor self-esteem. ${ }^{3-6}$ In regard to the measurement of body image construct, it must be noted that body image has generally been considered as a stable trait rather than as a situational variable (state). In regard to this bias, it is relevant to quantify the effects of one's body image on various self-experiences and life contexts (body image quality of life) and its relationships with other traditional methods to assess the construct. ${ }^{6}$
Correspondence: Ignacio Jáuregui-Lobera Virgen del Monte 3I, Seville 4I0II, Spain Tel +34954280789

Fax +34954278167

Email ignacio-ja@telefonica.net 
Eating disorders (ED) are among the most maladaptive manifestations of body image dysfunction and traditionally the treatment of body image disturbances is considered a relevant facet of the general treatment of ED. ${ }^{7}$ Patients with ED show physical, psychological, and social impairments with a negative impact on their quality of life. ${ }^{8,9} \mathrm{In}$ fact, a relationship between greater severity of ED symptoms and lower quality of life has been described. ${ }^{10,11}$ In regard to EDs, one of the core beliefs is related to body dissatisfaction while other thoughts and behaviors, such as eating and weight concerns, dieting, or binge eating, are associated with those core beliefs. As a whole, these core beliefs are negatively associated with the physical and mental health components of quality of life. ${ }^{12}$ Despite body image disturbances and body image quality of life having been a focus of study on college men and women, and on different medical conditions, there is a shortage of research on the impact of body image on the quality of life among ED patients. ${ }^{13}$

Besides body image and body image quality of life disturbances, EDs are characterized by different cognitive distortions such as the phenomenon of thought-shape fusion (TSF). TSF suggests that there is a strong relationship between the domains of importance of thoughts and control over thoughts and ED, particularly the link between thoughts and feelings related to body shape. The TSF construct consists of three components related to beliefs about the consequences of thinking about forbidden foods: (1) the belief that having such thoughts makes it more likely that the person will actually gain weight or change his or her shape (likelihood TSF); (2) the belief that having such thoughts is as immoral as actually eating the food (moral TSF); and (3) the belief that having such thoughts makes the person feel fat (feeling TSF). In the original description of TSF, the authors started from the hypothesis that people who make this distortion know rationally that thinking about forbidden foods does not really cause weight gain or changes in body shape, although this does not stop them from feeling this on an emotional level. ${ }^{14}$ It has been stated that, although they differ conceptually, the different components of TSF and the interpretation of thoughts would reflect a general construct, ie, giving undue importance to thoughts related to eating, body shape, and weight, and interpreting such thoughts as personally significant. ${ }^{15}$ Although some authors have suggested the need to determine the potential differences in the type of TSF shown by patients with anorexia, bulimia, and atypical disorders, grouping together all ED subtypes seems to be appropriate considering the transdiagnostic theory of ED. ${ }^{15,16}$ This justifies the use of samples including all types of ED patients. TSF is not specific to ED patients, but it is specific to thinking about eating fattening foods. ${ }^{17,18}$ This cognitive distortion has been induced experimentally in ED patients as well as in nonclinical participants. ${ }^{19,20}$

Some studies have linked TSF with different ED-related variables such as the subscales of weight and shape concern of the Eating Disorder Examination Questionnaire $(\mathrm{EDE}-\mathrm{Q})^{14}$ but there is a shortage of research focused on the concrete relationship among TSF, specific instruments to assess body image disturbances, and body image quality of life in ED patients. Thus, the aim of this study was to analyze these types of relationships in order to improve the understanding of the links between body image concerns and a specific bias consisting of beliefs about the consequences of thinking about forbidden foods. The specific hypotheses were: (1) considering the transdiagnostic theory of ED, differences between subgroups of ED with respect to the variables included in this study would not be expected; (2) there would be differences in the variables between patients with high versus low TSF; and (3) there would be significant correlations between TSF and body image-related variables that would be maintained after controlling for psychopathological variables.

\section{Materials and methods \\ Participants}

The initial sample included 80 participants, but it was reduced to 76 after rejecting four incomplete protocols. None of the participants showed any comprehension and/or language difficulties nor refused to participate. The final sample included $76 \mathrm{ED}$ patients (mean age $20.13 \pm 2.28$ years; 69 women and seven men) who fulfilled the diagnostic criteria of the Diagnostic and Statistical Manual of Mental Disorders, fourth edition, text revision (DSM-IV-TR) at the beginning of the treatment. All outpatients were receiving treatment at the Eating Disorders Unit of the Behavioral Sciences Institute (Seville, Spain). The sample of patients consisted of those who, at the moment of the study, had recovered a normal weight (mean body mass index $20.8 \pm 1.34$ ) and had no relevant associated psychopathology (they did not fulfill any diagnostic criteria for other psychopathologies apart from their ED, considering axis I diagnoses of the DSM-IV-TR). The possible presence of comorbid disorders was determined by a clinical interview. Written informed consent was obtained from all participants. 


\section{Measures}

Thought-Shape Fusion Questionnaire (TSF-Q)

The TSF-Q measures the fusion between thoughts and body shape or image. ${ }^{14}$ It is a 34-item, self-report questionnaire that is divided into two sections: (1) a 17-item conceptual section that measures the importance attached to thoughts related to eating and the body; and (2) a 17-item interpretative section that evaluates how these thoughts are interpreted by participants. Each item is scored from zero (not at all) to four (completely), according to how much the subject agrees with its content. The Spanish version of the questionnaire has been shown to have high internal consistency (Cronbach's $\alpha=0.93-0.96){ }^{21}$

\section{The Spanish version of Body Image Quality} of Life Inventory (BIQLI)

BIQLI is a self-reported, 19-item questionnaire that is evaluated on a seven-point bipolar scale: from positive three (very positive effect) to zero (no impact) to negative three (very negative effect). ${ }^{6}$ The Spanish version of BIQLI was used for the current study, which has shown high internal consistency (Cronbach's $\alpha=0.95$ ) and high stability over a 3 -week period (test-retest reliability of $r=0.84$ ). ${ }^{22}$

\section{The Spanish version of the Body Appreciation Scale (BAS)}

This 13-item instrument, with a single-dimension factor structure, shows adequate internal consistency (Cronbach's $\alpha=0.91$ ) and construct validity. It is useful for studying the positive aspects of body image (a favorable opinion about one's physical features, an acceptance of one's body despite its weight, shape, or imperfections, respect and attention towards the body's needs through the adoption of healthy behaviors, and self-protection by rejecting body ideals presented in the media). BAS items are rated on a five-point scale from one (never) to five (always) and averaged to obtain an overall body appreciation score. When giving the BAS to men, item 12 is revised to: "I do not allow unrealistically muscular images of men presented in the media to affect my attitudes toward my body."23,24

\section{The Spanish version of the Body Shape Questionnaire (BSQ)}

The Spanish version of this questionnaire was used, which has adequate psychometric properties (Cronbach's $\alpha=0.95-0.97$ ). This instrument has 34 items that are rated on a six-point scale from one (never) to six (always). The total score ranges between 34 and 204 and four factors are evaluated: body dissatisfaction, feelings of low self-esteem due to appearance, drive for thinness, and fear of gaining weight. ${ }^{25,26}$
Eating Disorders Inventory-2 (EDI-2)

For this study, the seven-item Drive for Thinness (DT) subscale and nine-item Body Dissatisfaction (BD) subscale were administered. The BD subscale measures dissatisfaction with the overall shape and size of those parts of the body mostly related to ED. The DT subscale measures excessive concern with dieting, preoccupation with weight, and fear of weight gain. The internal consistency of the test, and its subscales, ranges between $0.83-0.92$ in patient samples and between $0.65-0.93$ in various nonclinical samples. Test-retest reliability ranges between $0.41-0.97$ depending on the sample. ${ }^{27}$

\section{Symptom Checklist-90-Revised (SCL-90-R)}

This 90 -item self-report instrument measures nine dimensions of psychological symptoms and yields three global indexes of distress. The measured dimensions are somatization, obsessive-compulsive, interpersonal sensitivity, depression, phobic anxiety, hostility, paranoid ideation, and psychoticism. The ninth subscale refers to miscellaneous symptoms, as low factor loading prevents them from being included in the other subscales. The SCL-90-R also yields three global indexes of distress that measure the severity of general psychopathology: (1) the Global Severity Index (GSI), which measures the degree of general distress; (2) the Positive Symptom Total (PST), which refers to the number of symptoms reported by the subject; and (3) the Positive Symptom Distress Index (PSDI), which measures the intensity of symptoms and relates general distress with the number of symptoms. Cronbach's $\alpha$ ranges between 0.81 and 0.90 , and the instrument shows adequate concurrent and predictive validity. The Spanish version of the SCL-90-R was used in this study. ${ }^{28,29}$

\section{State-Trait Anxiety Inventory (STAI)}

This is a 40-item, self-report questionnaire that measures state anxiety (STAI-S) and trait anxiety (STAI-T). Items are scored from zero (not at all) to three (a lot). The STAI items show a sufficient ability to discriminate and differentiate (between age, sex, and anxiety levels), with good internal consistency (Cronbach's $\alpha=0.90-0.93$ for the STAI-S; Cronbach's $\alpha=0.84-0.87$ for the STAI-T). The Spanish version of STAI was used in the current study. ${ }^{30,31}$

Keeping in mind that the phenomenon of TSF has been found to be related with eating disturbances and does not seem to be mediated by other variables such as anxiety, depression, or obsessionality, ${ }^{14,15,17}$ both STAI and SCL-90-R were used in the current study. 


\section{Procedure}

After obtaining informed consent from all participants, the abovementioned questionnaires were administered to the patients. This was done in individual sessions with no time limit and in an adequate therapeutic context (ie, spacious room, light, noise). Each patient's therapist was present at the beginning of the session and explained how to complete the questionnaire. Having ensured that the instructions had been understood, the therapist then left the room so as not to be present while the patient completed the measures. The therapist then returned at the end of the session. Participation was completely voluntary and none of the participants received any form of recompense. The study was conducted between January and May 2012.

\section{Statistical analysis}

The Kolmogorov-Smirnov test was used to determine whether the data fitted a normal distribution and the Levene test was used to explore the similarity between variances. Taking into account the results and the small sample size, comparisons were analyzed using the nonparametric Kruskal-Wallis and Mann-Whitney tests. Nonparametric Spearman correlation coefficients (rho) were calculated in order to analyze the association between the different variables taken into account in this study. All analyses were performed using SPSS $^{\circledR}$ version 16 (IBM Corporation, Armonk, NY).

\section{Results \\ Characteristics}

Participants were patients suffering from anorexia nervosa $(\mathrm{n}=30)$, bulimia nervosa $(\mathrm{n}=19)$, and ED not otherwise specified $(\mathrm{n}=17)$. Table 1 shows the mean and standard deviation for all the variables included in the study. The Kruskal-Wallis test revealed significant higher scores in bulimia nervosa and ED not otherwise specified than in anorexia nervosa with respect to TSF-interpretative $(\mathrm{H}=7.25 ; P<0.05)$, EDI-DT $(\mathrm{H}=9.71 ; P<0.01)$, and EDI-BD $(\mathrm{H}=12.36 ; P<0.01)$.

\section{Correlations between TSF-Q and body image-related variables}

These bivariate correlations are shown in Table 2 . In order to test the possible influence of psychopathological variables on these correlations, Spearman coefficients were obtained

Table I Descriptive statistics (mean \pm standard deviation)

\begin{tabular}{|c|c|c|c|}
\hline & AN & BN & EDNOS \\
\hline \multicolumn{4}{|l|}{ Thought-Shape Fusion Questionnaire (TSF-Q) } \\
\hline TSF-conceptual & $17.91 \pm 16.50$ & $23.75 \pm 20.54$ & $25.23 \pm 17.62$ \\
\hline TSF-interpretative & $17.29 \pm 17.22$ & $30.13 \pm 21.64$ & $32.62 \pm 20.34$ \\
\hline TSF-total & $38.26 \pm 36.14$ & $54.33 \pm 40.04$ & $57.85 \pm 34.96$ \\
\hline Body Image Quality of Life Inventory (BIQLI) & $-0.39 \pm 1.23$ & $-1.12 \pm 1.25$ & $-0.72 \pm 1.14$ \\
\hline Body Appreciation Scale (BAS) & $40.90 \pm 8.75$ & $36.58 \pm 11.87$ & $35.69 \pm 8.48$ \\
\hline Body Shape Questionnaire (BSQ) & $89.42 \pm 36.84$ & $121.33 \pm 48.12$ & $108.07 \pm 40.55$ \\
\hline \multicolumn{4}{|l|}{ Eating Disorders Inventory-2 (EDI-2) } \\
\hline Drive for thinness (DT) & $6.79 \pm 6.66$ & $1 \mathrm{I} .75 \pm 7.55$ & $12.36 \pm 5.75$ \\
\hline Body dissatisfaction (BD) & $8.77 \pm 6.77$ & $12.00 \pm 9.73$ & $18.07 \pm 5.96$ \\
\hline \multicolumn{4}{|l|}{ Symptoms Checklist-90-Revised (SCL-90-R) } \\
\hline Somatizations & $0.85 \pm 0.71$ & $1.20 \pm 1.07$ & $0.89 \pm 0.93$ \\
\hline Obsessive-compulsive & $1.17 \pm 0.74$ & $1.50 \pm 1.16$ & $1.12 \pm 0.73$ \\
\hline Interpersonal sensitivity & $1.30 \pm 0.94$ & $1.68 \pm 1.26$ & $1.44 \pm 1.03$ \\
\hline Depression & $1.35 \pm 0.95$ & $1.65 \pm 1.14$ & $1.45 \pm 0.95$ \\
\hline Anxiety & $1.07 \pm 0.93$ & $1.26 \pm 1.10$ & $0.98 \pm 0.72$ \\
\hline Hostility & $1.09 \pm 0.96$ & $1.16 \pm 1.02$ & $0.91 \pm 0.95$ \\
\hline Phobic anxiety & $0.40 \pm 0.44$ & $0.76 \pm 0.81$ & $0.50 \pm 0.87$ \\
\hline Paranoid ideation & $0.94 \pm 0.75$ & $0.91 \pm 0.88$ & $0.88 \pm 0.55$ \\
\hline Psychoticism & $0.94 \pm 0.85$ & $1.10 \pm 0.87$ & $0.80 \pm 0.70$ \\
\hline Global Severity Index & $1.05 \pm 0.71$ & $1.29 \pm 0-93$ & $1.13 \pm 0.69$ \\
\hline Positive Symptom Total & $45.82 \pm 20.12$ & $51.37 \pm 25.22$ & $44.53 \pm 22.79$ \\
\hline Positive Symptom Distress Index & $1.87 \pm 0.64$ & $1.89 \pm 0.97$ & $1.91 \pm 0.48$ \\
\hline \multicolumn{4}{|l|}{ State-Trait Anxiety Inventory (STAI) } \\
\hline Trait anxiety (STAI-T) & $30.03 \pm|0.5|$ & $35.06 \pm 10.56$ & $31.67 \pm 9.86$ \\
\hline State anxiety (STAI-S) & $28.54 \pm 15.07$ & $26.69 \pm 15.94$ & $26.67 \pm 13.06$ \\
\hline
\end{tabular}

Abbreviations: AN, anorexia nervosa; BN, bulimia nervosa; EDNOS, eating disorders not otherwise specified. 
after controlling for the psychopathological variables (SCL90-R and STAI). Despite having observed a small decrease in the coefficients, it must be noted that the correlations generally remained significant. The correlations of TSFconceptual with BSQ, BAS, EDI-DT, and EDI-BD were $0.60(P<0.01),-0.35(P<0.01), 0.61(P<0.01)$, and $0.54(P<0.01)$, respectively. The correlations of TSFinterpretative with BSQ, BAS, EDI-DT, and EDI-BD were $0.67(P<0.01),-0.53(P<0.01), 0.64(P<0.01)$, and 0.65 $(P<0.01)$, respectively. Finally, TSF-total correlated with BSQ $($ Rho $=0.67 ; P<0.01)$, BAS $($ Rho $=-0.47 ; P<0.01)$, EDI-DT $($ Rho $=0.59 ; P<0.01)$, and EDI-BD $($ Rho $=0.60$; $P<0.01)$. Figure 1 shows the matrix scatter plot with the corresponding linear fit method. Figure 1 shows the matrix scatter plot with the corresponding linear fit method.

\section{High versus low TSF-Q}

Considering the scores on TSF-Q (conceptual, interpretative, and total), the sample was divided into two groups: high TSF (percentile $\geq 75$ ) and low TSF (percentile $<75$ ). The possible differences between the two subgroups were explored using the Mann-Whitney U-test. The results are shown in Table 3 with mention of the significant differences found.

\section{Discussion}

It has been stated that TSF may lead to certain maladaptive cognitive strategies. Thus, if a person believes that thoughts have an influence on weight and/or shape, he/she is likely to engage in avoidance of such thoughts. TSF may elicit checking behaviors, which maintain body image distortions, and hence challenging TSF might serve to reduce checking behavior. With regard to TSF and body image-related variables, relationships found in the current study confirm those reported by other authors. Shafran and Robinson found a significant correlation between TSF (conceptual and interpretative) and the subscales of Shape Concern and

Table 2 Correlations (Spearman's rho coefficient) between thought-shape fusion and body image-related variables

\begin{tabular}{llllll}
\hline & BIQLI & BAS & BSQ & EDI-DT & EDI-BD \\
\hline TSF-conceptual & -0.18 & $-0.35^{* *}$ & $0.60^{* *}$ & $0.61^{* *}$ & $0.54^{* *}$ \\
TSF-interpretative & $-0.28^{*}$ & $-0.53^{* *}$ & $0.67^{* *}$ & $0.64^{* *}$ & $0.65^{* *}$ \\
TSF-total & -0.11 & $-0.47^{* *}$ & $0.67^{* *}$ & $0.59^{* *}$ & $0.60^{* *}$ \\
\hline
\end{tabular}

Notes: $* P<0.05 ; * * P<0.01$

Abbreviations: BAS, Body Appreciation Scale; BIQLI, Body Image Quality of Life Inventory; BSQ, Body Shape Questionnaire; EDI-BD, Eating Disorder Inventory Body Dissatisfaction; EDI-DT, Eating Disorder Inventory - Drive for Thinness; TSF, Thought-shape fusion.

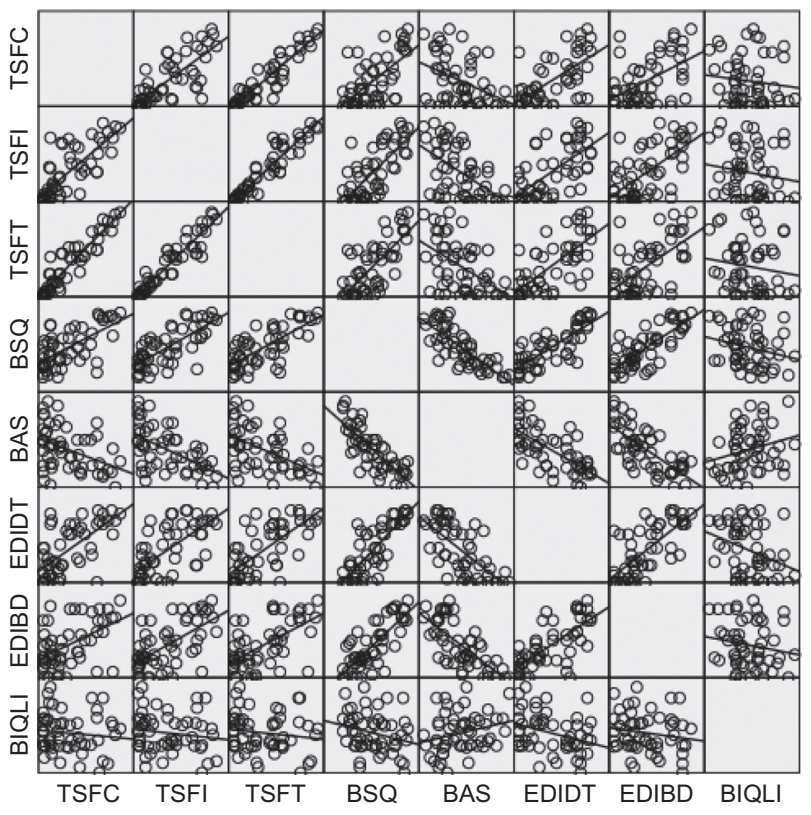

Figure I Correlations between thought-shape fusion (conceptual, interpretative, and total) and body image-related variables.

Abbreviations: BAS, Body Appreciation Scale; BIQLI, Body Image Quality of Life Inventory; BSQ, Body Shape Questionnaire; EDI-BD, Eating Disorder Inventory Body Dissatisfaction; EDI-DT, Eating Disorder Inventory - Drive for Thinness; TSFC, thought-shape fusion-conceptual; TSFI, thought-shape fusion-interpretative; TSFT, thought-shape fusion-total.

Weight Concern of the ED Examination Questionnaire. ${ }^{15}$ In $\mathrm{ED}$, the overimportance of thoughts about eating is accepted to be an expression of the overevaluation of eating, shape, weight, and their control. In addition, it might be that TSF is both a direct expression of the core psychopathology and also serves to maintain it. In this regard, it is not surprising that those patients who have higher TSF total score show more general psychopathology as well as poorer scores on those instruments related to body image except on the BIQLI. It could be said that ED patients show a negative body image quality of life regardless of the level of TSF. In regard to the relationship between TSF and body imagerelated variables, previous studies have reported significant correlations between TSF and the DT and BD subscales of EDI-2. ${ }^{21}$ Recently, in a study based on bulimic patients, it has been shown that TSF triggers different results including heightened levels of body dissatisfaction. ${ }^{32}$

To the authors' knowledge, this is the first study including different measures of body image disturbances as well as the phenomenon of TSF and the concept of body image quality of life in patients with ED. This study shows that ED patients with a higher score on TSF have higher scores in the DT and BD subscales of EDI-2 as well as in the BSQ. In addition, they have a lower score on the BAS, which 
Table 3 High versus low Thought-Shape Fusion (TSF) total (mean \pm standard deviation)

\begin{tabular}{|c|c|c|c|}
\hline & High TSF & Low TSF & $\boldsymbol{P}$ \\
\hline Body appreciation (BAS) & $30.80 \pm 6.37$ & $41.27 \pm 9.68$ & $<0.0001$ \\
\hline Body shape (BSQ) & $148.93 \pm 36.06$ & $86.65 \pm 34.02$ & $<0.0001$ \\
\hline Body image quality of life (BIQLI) & $-0.64 \pm 1.40$ & $-0.57 \pm 1.11$ & 0.664 \\
\hline \multicolumn{4}{|l|}{ Eating Disorders Inventory-2 } \\
\hline Drive for thinness (EDI-DT) & $15.21 \pm 5.59$ & $7.19 \pm 6.55$ & $<0.0001$ \\
\hline Body dissatisfaction (EDI-BD) & $18.68 \pm 6.82$ & $8.61 \pm 6.70$ & $<0.0001$ \\
\hline \multicolumn{4}{|l|}{ Symptoms Checklist (SCL-90-R) } \\
\hline Somatizations & $1.56 \pm 1.11$ & $0.75 \pm 0.64$ & $<0.01$ \\
\hline Obsessive-compulsive & $2.02 \pm 0.93$ & $0.99 \pm 0.69$ & $<0.0001$ \\
\hline Interpersonal sensitivity & $2.29 \pm 0.90$ & $1.11 \pm 0.90$ & $<0.000$ I \\
\hline Depression & $2.28 \pm 0.91$ & $1.24 \pm 0.86$ & $<0.000$ I \\
\hline Anxiety & $1.83 \pm 1.13$ & $0.83 \pm 0.69$ & $<0.0001$ \\
\hline Hostility & $1.60 \pm 1.15$ & $1.00 \pm 0.88$ & $<0.05$ \\
\hline Phobic anxiety & $0.95 \pm 0.77$ & $0.33 \pm 0.51$ & $<0.01$ \\
\hline Paranoid ideation & $1.66 \pm 0.88$ & $0.73 \pm 0.55$ & $<0.000$ I \\
\hline Psychoticism & $1.51 \pm 0.77$ & $0.75 \pm 0.70$ & $<0.000$ I \\
\hline Global Severity Index (GSI) & $1.79 \pm 0.92$ & $0.80 \pm 0.59$ & $<0.0001$ \\
\hline Positive Symptom Total (PST) & $65.26 \pm 19.11$ & $41.29 \pm 18.83$ & $<0.000$ I \\
\hline Positive Symptom Distress Index (PSDI) & $2.34 \pm 0.64$ & $1.78 \pm 0.59$ & $<0.01$ \\
\hline \multicolumn{4}{|l|}{ State-Trait Anxiety Scale (STAI) } \\
\hline Trait anxiety (STAI-T) & $40.11 \pm 7.32$ & $28.63 \pm 9.97$ & $<0.0001$ \\
\hline State anxiety (STAI-S) & $37.42 \pm 12.67$ & $25.22 \pm 13.79$ & $<0.01$ \\
\hline
\end{tabular}

measures the positive aspects of body image (a favorable opinion about one's physical features, an acceptance of one's body despite its weight, shape, or imperfections, respect and attention towards the body's needs through the adoption of healthy behaviors, and self-protection by rejecting body ideals presented in the media). ${ }^{23}$ Surprisingly, there were no significant correlations between body image quality of life (as measured by the BIQLI) and TSF (conceptual and total). Nevertheless, a significant correlation was found between BIQLI and TSF-interpretative. It must be noted that the main problem in measuring the body image construct has been to consider it as a stable trait rather than as a situational variable state. ${ }^{6} \mathrm{BIQLI}$ is a self-reported questionnaire that quantifies the influence of one's body image experiences on multiple relevant facets of psychosocial functioning and wellbeing in everyday life (more state than trait). ${ }^{6}$ The interpretative subscale of TSF is concerned about how an individual interprets the fact of eating certain foods. ${ }^{14}$ It could explain that a specific situation (thinking about eating some foods) may be more related to a measure of body image, which highlights specific experiences, than with other measures more focused on the body image as a stable trait.

Apart from specific body image-related variables, patients with positive and negative body image quality of life show differences with respect to TSF (conceptual, interpretative, and total) as well as in regard to different psychopathological variables, which undoubtedly seem to influence the body image quality of life of these patients. In the current study, patients with a negative body image quality of life showed higher scores in Positive Symptom Total, Global Severity Index, depression, anxiety, somatization, and obsessivecompulsive as measured by the SCL-90-R, and higher scores in state anxiety (STAI-S). These results partially confirm those recently reported in regard to BIQLI. ${ }^{13}$

Among outpatients with ED undergoing treatment, after recovering a normal weight and regardless of the length of treatment, there appears to be two subgroups with respect to the phenomenon of TSF. These two subgroups (high versus low TSF) show differences in several body image-related variables and some psychopathological variables. Overall, the different body image-related variables are linked with TSF distortion, thus demonstrating a relationship between concrete thoughts (eg, eating forbidden foods) and weight/shape.

There were some limitations in the current study. The small number of men $(n=7)$ was a limitation in being able to study possible sex differences. A more representative sample of men is necessary for future studies, as well as a larger number of patients of the different ED subgroups in order to 
analyze theoretical differences between them. Nevertheless, specifically with respect to TSF, previous research has not demonstrated such differences.

\section{Conclusion}

Despite some studies linking TSF with different ED-related variables, there is a shortage of research focused on the concrete relationship among TSF, specific instruments to assess body image disturbances, and body image quality of life in ED patients. The current study analyzes these relationships showing the interrelation between different body image-related variables, the link between TSF and these body image aspects, and the differences with respect to psychopathological variables.

\section{Acknowledgments}

The authors acknowledge the support of the Eating Disorders Unit of the Behavioral Sciences Institute, which supported the preparation of this manuscript. Especially, thanks to Barry Kenna for his technical support.

\section{Disclosure}

The authors report no conflicts of interest in this work.

\section{References}

1. Cash TF, Pruzinsky T, editors. Understanding body images: historical and contemporary perspectives. Body Image: A Handbook of Theory, Research, and Clinical Practice. New York, NY: Guilford Press; 2002:3-12.

2. Thompson JK, Heinberg LJ, Altabe M, Tantleff-Dunn S. Exacting Beauty: Theory, Assessment, and Treatment of Body Image Disturbance. Washington, DC: American Psychological Association; 1999.

3. Cash TF. Cognitive-behavioral perspectives on body image. In: Cash TF, Pruzinsky T, editors. Body Image: A Handbook of Theory, Research, and Clinical Practice. New York, NY: Guilford Press; 2002: 38-46.

4. Cash TF. The psychology of physical appearance: aesthetics, attributes, and images. In: Cash TF, Pruzinsky T, editors. Body Images: Development, Deviance, and Change. New York, NY: Guilford Press; 1990:51-79.

5. Cash TF. Body-image attitudes: evaluation, investment, and affect. Percept Mot Skills. 1994;78(3 Pt 2):1168-1170.

6. Cash TF, Fleming EC. The impact of body image experiences: development of the body image quality of life inventory. Int $J$ Eat Disord. 2002;31(4):455-460.

7. Cash TF, Hrabosky JI. Treatment of body image disturbances. In: Thompson JK, editor. Handbook of Eating Disorders and Obesity. Hoboken, NJ: John Wiley \& Sons; 2004:515-541.

8. de la Rie SM, Noordenbos G, van Furth EF. Quality of life and eating disorders. Qual Life Res. 2005;14(6):1511-1522.

9. Doll HA, Petersen SE, Stewart-Brown SL. Eating disorders and emotional and physical well-being: associations between student selfreports of eating disorders and quality of life as measured by the SF-36. Qual Life Res. 2005;14(3):705-717.

10. Hay PJ, Mond JM. How to "count the cost" and measure burden? A review of health-related quality of life in people with eating disorders. J Ment Health. 2005;14(6):539-552.
11. Mond JM, Hay PJ, Rodgers B, Owen C, Beumont PJV. Temporal stability of the Eating Disorder Examination Questionnaire. Int J Eat Disord. 2004:36(2):195-203.

12. Vallance JK, Latner JD, Gleaves DH. The relationship between eating disorder psychopathology and health-related quality of life within a community sample. Qual Life Res. 2010;20(5): 675-682.

13. Jauregui Lobera I, Bolanos Rios P. Body image quality of life in eating disorders. Patient Prefer Adherence. 2011;5:109-116.

14. Shafran R, Teachman BA, Kerry S, Rachman S. A cognitive distortion associated with eating disorders: thought-shape fusion. $\mathrm{Br} J \mathrm{Clin}$ Psychol. 1999;38(Pt 2):167-179.

15. Shafran R, Robinson P. Thought-shape fusion in eating disorders. $\mathrm{Br}$ J Clin Psychol. 2004;43(Pt 4):399-408.

16. Garner DM, Bemis KM. A cognitive-behavioral approach to anorexia nervosa. Cognit Ther Res. 1982;6(2):123-150.

17. Coelho JS, Carter JC, McFarlane T, Polivy J. "Just looking at food makes me gain weight": experimental induction of thought-shape fusion in eating-disordered and non-eating-disordered women. Behav Res Ther. 2008;46(2):219-228.

18. Coelho JS, Roefs A, Jansen A. The role of food-cue exposure and negative affect in the experience of thought-shape fusion. J Behav Ther Exp Psychiatry. 2010;41(4):409-417.

19. Radomsky AS, de Silva P, Todd G, Treasure J, Murphy T. Thought-shape fusion in anorexia nervosa: an experimental investigation. Behav Res Ther. 2002;40(10):1169-1177.

20. Jauregui Lobera I, Santed MA, Bolanos Rios P, Ruiz Prieto I, Santiago Fernandez MJ, Garrido Casals O. Experimental induction of thoughtshape fusion in eating disorder patients: the role of coping strategies. Nutr Hosp. 2011;26(6):1402-1411.

21. Jauregui Lobera I, Santed MA, Shafran R, Santiago MJ, Estebanez S. Psychometric properties of the Spanish version of the Thought-Shape Fusion Questionnaire. Span J Psychol. 2012;15(1):410-423.

22. Jauregui Lobera I, Bolanos Rios P. Body image and quality of life in Spanish population. Int J Gen Med. 2011;4:63-72.

23. Avalos L, Tylka TL, Wood-Barcalow N. The Body Appreciation Scale: development and psychometric evaluation. Body Image. 2005;2(3): 285-297.

24. Jauregui Lobera I, Bolanos Rios P. Spanish version of the Body Appreciation Scale (BAS) for adolescents. Span J Psychol. 2011;14(1): 411-420.

25. Cooper PJ, Taylor MJ, Cooper Z, Fairburn CG. The development and validation of the Body Shape Questionnaire. Int J Eat Disord. 1987;6(4): 485-494.

26. Raich RM, Mora M, Soler A, Avila C, Clos I, Zapater L. Adaptacion de un instrumento de evaluacion de la insatisfaccion corporal [Adaptation of an instrument to evaluate body dissatisfaction]. Clinica y Salud. 1996;7(1):51-66. Spanish.

27. Garner DM. Inventario de Trastornos de la Conducta Alimentaria-2 [Eating Disorders Inventory-2]. Madrid: Tea Ediciones; 1998. Spanish.

28. Derogatis LR. The SCL-90-R: Administration, Scoring, and Procedures Manual-II for the Revised Version and Other Instruments of the Psychopathology Rating Scale. Towson, MD: Clinical Psychometric Research; 1983.

29. Gonzalez de Rivera JL, Derogatis LR, de las Cuevas C, et al. The Spanish Version of the SCL-90-R. Normative Data in the General Population. Towson, MD: Clinical Psychometric Research; 1989.

30. Spielberger CD, Gorsuch RL, Lushene RE. Manual for the State-Trait Anxiety Inventory. Palo Alto, CA: Consulting Psychologist Press; 1970.

31. Seisdedos N. STAI: Cuestionario de Ansiedad Estado-Rasgo [State-Trait Anxiety Inventory]. Madrid: TEA Ediciones; 1982. Spanish.

32. Kostopoulou M, Varsou E, Stalikas A. Thought-shape fusion in bulimia nervosa: an experimental investigation. Eat Weight Disord. 2011;16(2): e86-e92. 


\section{Publish your work in this journal}

The International Journal of General Medicine is an international, A key focus is the elucidation of disease processes and management peer-reviewed open-access journal that focuses on general and internal medicine, pathogenesis, epidemiology, diagnosis, monitoring and treatment protocols. The journal is characterized by the rapid reporting of reviews, original research and clinical studies across all disease areas. protocols resulting in improved outcomes for the patient.The manuscript management system is completely online and includes a very quick and fair peer-review system. Visit http://www.dovepress.com/ testimonials.php to read real quotes from published authors.

Submit your manuscript here: http://www.dovepress.com/international-journal-of-general-medicine-journal 